\title{
A CASE STUDY ON THE SUCCESS FACTORS OF TARGET VALUE DESIGN
}

\author{
Patricia A. Tillmann ${ }^{1}$, Doanh Do ${ }^{2}$, Glenn Ballard ${ }^{3}$
}

\begin{abstract}
Target Value Design (TVD) has extensively been adopted in Integrated Project Delivery (IPD) environments in the U.S. Drawn from a profit planning approach used in the manufacturing industry called Target Costing (TC), TVD supports integrated project teams to plan and deliver projects for an agreed target cost. Research on TVD has revealed the success rate for delivering a project at or below the agreed target varies, and the results does not always meet expectations. Therefore, the aim of this paper was to report on lessons learned from an in depth case study that can contribute to advance the knowledge and improve the practical application of TVD on IPD projects. The research reported in this paper is part of an overarching research effort to improve the adoption of lean construction methods in the context of IPD-ish type of projects for the public sector in California. As multiparty agreements is not an option available for organizations in the public sector, this research effort focuses on understanding the underlying mechanisms of IPD in addition to contextual elements that can influence the successful application of TVD.
\end{abstract}

Keywords: Target Value Design, Target Costing, Integrated Project Delivery

\section{INTRODUCTION}

Target Value Design (TVD) is a lean construction method that has gained increased popularity over the years in the U.S., especially in Integrated Project Delivery (IPD) type of projects. The origins of TVD can be traced back to Target costing (TC), a practice used in new product development and popular in the car manufacturing industry. One fundamental principle of this method is viewing cost as an input to the product development process, instead of an output. Coupling this principle with transparency and cost tracking, TVD supports integrated project teams to plan and manage production costs in a setting where risks and rewards are shared (typical characteristic of an IPD environment).

The first successful TVD application in construction was reported by Ballard and Reiser (2004) in a Design-Build project in the USA. Since then, owners adopting TVD in IPD type of projects have reported significant improvement in performance (Conwell, 2012). However, a recent study based on the experience of a poll of practitioners from California reveals that even with the support of IPD principles, e.g. early involvement of participants, multi-party agreement, and shared risk and reward structure, project teams are not always successful in delivering the project to an agreed target cost (Ballard et al. 2015).

\footnotetext{
Senior Lean Manager, University of California San Francisco, California, +14152799102, patricia.andretillmann@ucsf.edu

Co-founder, Paramount Decisions, California, +17146229754, doanhqdo@gmail.com

Director, Project Production Systems Laboratory, University of California Berkeley, California, +1415-

710-5531,gballard@berkeley.edu
} 
The research reported in this paper is part of an overarching research effort to improve the adoption of lean construction methods in the context of IPD-ish type of projects for the public sector in California. As multi-party agreements is not an option available for some organizations in the public sector (and against the policies of some organizations in the private sector), this research effort focuses on understanding the underlying mechanisms of IPD in addition to contextual elements that can influence the successful adoption of TVD. Within this context, the intent of this paper was to describe and discuss the findings of a case study in which the final cost of the project exceeded the target cost established by the integrated team. Findings are then compared to another case study in which the target cost was also exceeded. Lessons learned from both cases aim to contribute to the advancement in knowledge and to improve the adoption of IPD and TVD principles.

\section{LITERATURE REVIEW}

The origins of Target Value Design can be traced back to Toyota's Target Costing approach. Originally introduced in Japan under the name of Genka Kikaku, Target costing is an approach to reduce the overall cost of a product over its entire life cycle, with the help of a multidisciplinary team, formed by the different departments of a company and the active contribution from the supply chain (Kato, 1993). Target costing has been defined as a "system of profit planning and cost management that is price led, customer focused, design centred, and cross functional" (Ansari et al., 1997). In target costing, market price for a new product is not determined by adding a profit margin to cost (e.g. cost-plus approach); instead, an allowable cost is determined by a target price less an appropriate profit margin (Kato, 1993).

The major contribution of TC is that it shifted the understanding of "production cost" from a fixed value (with profit and market price as variables), to production cost being variable (with profit and market price established upfront).

$$
\text { Market price (fixed, determined 1st) - Target profit = Production cost (result) }
$$

In the construction industry, the first effort to implement target costing was in the UK, on two military housing projects (Nicolini et al., 2000). The same authors observed several challenges to implement such an approach in the construction industry, including the industry-level fragmentation, the culture of companies being "adversaries" and the traditional cost-plus approach used in the construction industry.

The first reported successful case of TC adoption was in the construction of St. Olaf's College in Northfield, Minnesota, completed in 2002 (Ballard and Reiser, 2004). As the popularity of this approach increased in the construction industry, new reflections about its meaning and application emerged. In 2007, the term Target Value Design was coined and replaced the name 'Target Costing' (see Macomber et al. 2007). Since then, several projects in the U.S. have adopted TVD, and the lessons learned from this experience has led to the publication and periodic revision of a benchmark to support the adoption of TC in construction (e.g. Ballard 2005; 2008; 2011).

Although TVD can be implemented in any type of project, it is common practice to adopt such method in IPD type of projects. Through multi-party agreements that prescribe desired means and behaviours, IPD provides the contractual support for project teams to align their commercial interests, achieve organizational integration (i.e., downstream players involved in upstream processes and vice-versa), adopt lean management 
philosophy and methods (including TVD), and use appropriate technologies that support integrated work, dissolving silos.

However, even with the supporting environment of IPD, sometimes project teams have exceeded the target cost at the end of projects. On a study done in retrospect with a project team, Ballard et al. (2015) highlight some of the difficulties faced by the team in delivering the project for an agreed target cost, including:

- Difficulty of tracking changes in scope during design with associated impact on costs;

- Reducing escalation to zero and reducing estimates too early during pre-construction;

- Collaboration issues with consultants not on the risk pool;

- Design problems cascading into execution delay and impact on interdependent systems;

- Extensive use of overtime to recover from delay;

- Lack of a transparent and shared productivity measuring system;

- Contingency set too low for the complexity of the building; and

- Drastic increase in general conditions towards the end of the project.

The same authors highlight major concerns for the success of TVD and IPD, including: (a) teams setting up fair deals with the owners upfront; (b) being able to choose their partners in the risk pool; (c) tracking and controlling costs throughout project execution (and not only design). This paper expands on that discussion and presents another case in which the target cost was exceeded, identifying similarities and differences to the case reported.

\section{RESEARCH METHOD}

IPD and TVD have been popularly prescribed together for the success of projects. Both approaches are based on various managerial principles, that together support project teams to generate optimal project results. However, in practice there are contextual factors and nuances on how these approaches are implemented that affect expected results. In order to refine the understanding of these factors and improve the application of TVD and IPD principles in practice (allowing it to be transferred to contexts where full IPD is not possible), a design science research approach was chosen.

Design science research supports not only the creation of new artefacts to solve problems but also the refinement of existing ones through the evaluation of their implementation. The focus of this research is not on devising new artefacts but on evaluating the adoption of TVD and IPD principles to confirm their intended consequences, identifying factors that contribute for their success.

The typical research strategy adopted in design science research is multiple case studies (Van Aken, 2004). To date, the authors of this paper collected data on seven TVD and IPD projects, two of which have exceeded the target cost. One of the cases was described in Ballard et al. (2015), the second one is the focus of this paper.

The project reported on this paper was a $\sim 500,000 \mathrm{sq} \mathrm{ft}$ Hospital project, that took 10 years to be delivered - from conceptual design to execution, and did not achieve the desired target cost.

The project was observed for one year and data was collected through observant participation, interviews and focus groups. A total of (a) 17 decision-making meetings and 14 meetings with the IPD team were attended, (b) 15 interviews with project team members were realized and (c) three focus groups to generate lessons learned were facilitated. Follow up interviews were also realized with key stakeholders after the project was delivered. 


\section{CASE STUDY}

In this session, empirical observations are presented in a chronological manner, according to distinct phases of the project: early design, design development, construction documents and construction administration.

\subsection{Early design phase}

The project submitted their preliminary application to the city in 2003 . The integrated agreement was signed in 2006 and the project continued until mid-2009, when it was partially suspended due to capital funding constraints, a consequence of the 2008 economic downturn in the U.S.

As a result, the project team had to carry out a validation study to assess the feasibility of the project within the new funding constraints. It was the interest of all participants to move the project forward and the team worked hard to make the project economically feasible by adjusting project scope and exploring ways to reduce construction costs. Through this effort, the team was granted authorization to re-start the project in mid-2010 and a revised integrated agreement was signed.

At this stage, the close participation of owners as part of the integrated team allowed a better understanding of their business case and funding constraints, helping the team to design solutions that would make the project feasible again. According to project team members, this resulted in a very challenging starting point for TVD. With an aggressive allowable cost, the team decided to set a target cost arbitrarily $5 \%$ below the allowable cost to spur innovation.

\subsection{Design development phase}

During design development, the project team was organized in multidisciplinary clusters, and each cluster worked within an allowable cost and towards the established target cost. As design progressed and multiple stakeholders got involved, the project scope and estimated costs of construction varied drastically and an effort was made to maintain design within the allowable costs. Interviews with project team members illustrated the difficulty to track the evolution of scope and costs during that phase, highlighting three key factors. Firstly the presence of an owner represented by two organizations with different priorities: one organization responsible for managing the funds for construction and another organization that will occupy the building. This resulted in the need to negotiate many decisions, sometimes taking longer to achieve a conclusion. Secondly, a change in key decision-making stakeholders from the users representative group. New stakeholders came with a different mind-set, causing more changes than the project team had expected. Thirdly, the fact that the architects were part of the integrated team but were not co-located in the same office space. That made it more difficult to track the evolution and costs of design development in a more integrated manner because design changes would be incorporated in the drawings without a prior assessment of their impact. Finally, the fact that not all trades were part of the risk pool. The team perceived that it was harder to collaborate and get updated estimates of those companies that were not in the risk pool.

The changes in scope and the need to revise the original design was the reason for the architects renegotiating their fees in the project. During the interviews with team members it was observed that opinions were distinct about whether or not this negotiation was justified. As part of this negotiation, the owner decided to audit the design consultants' fees, which also increased the costs of the project. 
The opinion of some interviewees is that the risk pool and shared profit affects companies in different ways, depending on how their fees are set and how they traditionally make profit in projects. While there is a big incentive for general contractors to work in such terms, for companies that have their profit based on the amount of work they do, the benefits of shared savings must be higher than the profit opportunity based on amount of work.

Another aspect that was revealed during the interviews with the team was the lack of common understanding regarding how the decision making process within TVD should work: how the ideas should be vetted, who should approve them, how to better filter ideas that will impact the costs of the project and so forth. Team members joined the project in different points in time and the ideas of IPD and lean were new to many of them. The level of expertise with TVD varied greatly among team members and the project did not have an on-boarding process or formal training specific to those lean methods and techniques.

Despite these difficulties, during that stage, the co-location of GC and trade partners, the multi-disciplinary cluster organization, training on lean production principles and extensive use of BIM was very positive to stimulate project team members to find creative ways to reduce project costs. Based on their technical expertise, team members were able to explore design alternatives with similar performance but that would cost less to produce. A few examples of value engineering ideas resulting from an analysis of building configuration included:

- Changing the configuration of interior partitions to an alternative that presented an equal acoustic performance but would be less expensive to install

- Pre-mounted sink, involving multi-disciplinary components reducing field installation hours

- Modularizing and optimizing the design of glass panels to avoid waste of material In addition, as design progressed, project estimators started to produce estimates with greater accuracy based on detailed information about building components. Greater accuracy of estimates and allocation of reduced escalation were two components that contributed to reducing expected costs and getting close to the target cost.

\subsection{Construction documents phase}

As the team approached the end of the design development phase and scope changes were stabilized, it was time to agree on an estimated maximum price. In that stage, the team made a commitment to deliver the project for an agreed target, setting the basis for a risk and reward distribution at the end of the project.

The cluster organization and collaboration among trade partners also contributed to designing a production system that would generate savings for the project team. Those savings were not only a result of designing multi-disciplinary and pre-fabricated solutions to increase productivity but also by coming up with efficient ways to install interconnected systems, sharing the savings from reduced field hours.

By using lean principles to achieve simplification through pre-fabrication and continuous flow, the project team was able to achieve efficiencies during the construction phase. A factor that has contributed greatly for the team's ability to design an efficient production system was training and a shared understanding among trade partners about lean construction principles, methods and tools. A few examples observed include:

- Developing an integrated logistic plan to share and therefore reduce the costs of expensive rental equipment and machinery 
- Creating interdisciplinary plans that optimize the sequence of installation of interdependent building systems

- Pre-assembling building components to reduce man-power efforts in the job site

- Defining a material staging and tool distribution strategy that will reduce transportation effort

\subsection{Construction administration phase}

During the construction administration phase, the main focus of TVD was in tracking productivity and schedule. The team started to observe that one of the trades in the risk pool was falling behind and underperforming in terms of costs and schedule. At the end of the project, the team could not achieve the agreed target cost and the main reason was associated with the challenges faced by this particular trade during construction.

\section{DISCUSSION}

The observations made on this empirical case brought new insights to the success factors of TVD. The discussion is organized in chronological order and based on the formula previously presented:

$$
\text { Market price }- \text { Target profit }=\text { Production cost }
$$

\subsection{Market Price}

One important success factor of achieving a target cost seems to be tied to decisions made in the beginning of projects about market price. Uncertainties related to market fluctuations and how escalation will play throughout the years seems to be the first challenge for teams implementing TVD. In the analysed project, the team waited to commit to a target cost as much as they could. That way, they could understand how escalation would play during the construction period.

The benefit of IPD in this context is that the integrated team will bare together the uncertainty related to escalation. However, as observed by Ballard et al. (2005), a shared risk and reward structure by itself does not assure that the challenges related to escalation will be solved. A plan for managing and mitigating risks needs to be in place.

The shared responsibility of risks also supports teams to be less conservative about their estimates. As observed in this case study, during design development phase, the gap between expected costs and the target costs was reduced due to the refinement of estimates. The comfort level brought by sharing risks seems to be an important component for the success of TVD.

\subsection{Target Profit}

It was observed in this case study (which resonates with the findings in Ballard et al. 2015) that companies do not seem to be only after a profit. They seem to seek a long-term partnership with their clients or avoid the cancellation of the project (especially during market uncertainties), therefore willing to work around client's constraints to make the project feasible, accepting a stretched starting point for a target cost. This will influence the baseline to which final costs will be compared to and this baseline is set partially based on external factors that are out of the project's control.

Also, in construction, projects are temporary organizations formed by a group of companies, which sometimes may have different strategies for making profit. It was 
observed in this case, that for companies that have their profit based on the amount of work they do, the benefits of shared savings must be higher than the profit opportunity based on amount of work. Although the multi-party agreement of IPD intends to create a better alignment among these companies, it seems that there is still some work to be done in regards to creating incentives that are perceived as equal and fair by all team members.

In this case study, it was also observed that perceived the shared savings as an incentive, were able to shift scope of work not only during the design phase but also during construction. This resulted not only in better design solutions but also in gains to field productivity during construction.

\subsection{Production costs}

Based on the findings of this study, production costs in TVD seem to be determined by three major components: (a) product design - costs associated with how the building is designed, (b) process design - costs associated with the production system, and (c) service design - costs associated with maintaining a temporary organization.

Product design influences the costs associated with scope, spatial configurations, modularization, systems and material performance, etc.. As observed in this case study, IPD brings downstream players to upstream processes and integrates team players that would traditionally work in silos. Such integration allowed the project team to understand better the client's business case and avoid the discontinuity of the project, as well as improve the constructability of design solutions (noting that companies that were not collocated or not contractually integrated, were not as collaborative as the ones in the team).

Production system design influences the ability to gain savings during project execution due to greater efficiency. By sharing resources, focusing on multi-disciplinary collaboration and applying lean principles, the integrated team was able to achieve significant gains in productivity. However, in this stage, companies that might bring major risks to the project need to be incentivized to collaborate in identifying and managing risks - independently if they are signatory of the multi-party agreement. This includes tracking, reporting performance and collaborating to mitigate risks.

Finally, costs of services are related to the costs of maintaining a temporary organization. If those are not agreed and made transparent from the beginning of the project, it can result in distrust among the integrated team members later on and undermine the performance of the team as a whole.

\section{CONCLUDING REMARKS}

The aim of this paper was to describe and discuss the findings of a case study in which the final cost of the project exceeded the target cost. The intent was to understand factors that influence the success of TVD and IPD and in the future understand how to create a similar environment in non-IPD projects.

This case brought insights about external (little control over) and internal (the team has control over) factors that influence the ability of a team to deliver a project to a target cost. Achieving an agreed target cost, seems to depend on: (a) how the market price and target cost are set; (b) how shared profit is agreed upon and made transparent; and (c) how production costs (product-process-service) are steered towards the target cost and tracked, so risks can be identified and mitigated. 
The next steps of this research will be to further understand the influencing factors for the success of TVD and IPD on other case studies and explore the adaptation of these principles to a non-IPD environment.

\section{REFERENCES}

Ansari, S., J. Bell, J. Cam-I. Target Costing: The Next Frontier in Strategic Cost Management. Irwin, Chicago, 1997.

Ballard G., Dilsworth B., Do D., Low W., Mobley J., Phillips P., Reed D., Sargent Z., Tillmann P., and Wood N. (2015) How to Make Shared Risk and Reward Sustainable. In: Proc. International Group of Lean Construction Conference 23, Perth, Australia

Ballard, G; Reiser, P. The St. Olaf College Fieldhouse Project: A Case Study in Designing to Target Cost. Proceedings of the 12th annual conference of the International Group for Lean Construction, Elsinore, Denmark, August, 2004.

Ballard, G. The Lean Project Delivery System: An Update. Lean Construction Journal, pp.1-19, 2008. Retrieved from: www.leanconstruction.org in 28/07/2010.

Ballard, G. The Target Value Design: Current benchmark. Lean Construction Journal, pp.79-84, 2011.

Conwell, D., 2012. Sutter Health's Lean/Integrated Project Delivery Model. A P2SL Workshop: Owner Strategies for Project/Program Delivery, August 29, Berkeley, CA.

Kato, Y. Target costing support systems: lessons from leading Japanese companies, management accounting research, 4, pp. 33-47, 1993.

Macomber, H.; Howell, G.; Barberio, J. Target-Value Design: nine foundational practices for delivering surprising client value. The American Institute of Architects (AIA), 2007. Retrieved on 26/08/2010 from: http://www.aia.org/nwsltr_print.cfm?pagename=pm_a_112007_targetvaluedesign

Nicolini, D.; Tompkins, C.; Holti, R.; Oldman, A.; Smalley, M. Can Target Costing and Whole

Van Aken, J.E. Management research based on the paradigm of the design sciences: the quest for field-tested and grounded technological rules. Journal of Management Studies, v.41, n.2, pp.219-46, 2004. 